\title{
INFLUÊNCIA DE INOCULANTE BACTERIANO-ENZIMÁTICO SOBRE A MICROBIOTA E QUALIDADE NUTRICIONAL DE SILAGENS DE GRÃOS ÚMIDOS DE MILHO
}

\author{
Jaqueline Maria da Silva, ${ }^{1}$ Juliana Paiva Carnaúba, ${ }^{2}$ Izael de Oliveira Silva, ${ }^{3}$ Domingos Eduardo \\ Guimarães Tavares de Andrade, ${ }^{4}$ Edma Carvalho de Miranda ${ }^{5}$ e Edna Peixoto da Rocha Amorim ${ }^{5}$
}

1. Aluna do Programa de Pós-Graduação em Ciência Animal/PPCA, UFERSA, Mossoró-RN. E-mail: jaque_linemaria@yahoo.com.br 2. Aluna do Programa de Pós-Graduação em Fitopatologia/PPGF, UFRPE

3. Mestre do Programa de Pós-Graduação em Produção Vegetal/PPPV, UFAL

4. Doutor em Fitopatologia, Estação Experimental de Itapirema, Instituto Agronômico de Pernambuco/IPA, Goiana, PE

5. Professora adjunta, Departamento de Química, UFAL

5. Professora adjunta, Departamento de Agronomia, UFAL.

\section{RESUMO}

O objetivo deste trabalho foi avaliar a influência de inoculante bacteriano-enzimático sobre a microbiota e qualidade nutricional de silagens de grãos úmidos de milho. Aplicaram-se os seguintes tratamentos a silagens de grãos úmidos de milho: 1) sem inoculante; 2) com inoculante bacteriano (Lactobacillus casei e Streptococus faecalis); 3) com inoculante bacteriano e complexo enzimático ( $\alpha$-galactosidase e $\beta$-mananase); e 4 ) apenas com complexo enzimático. O material foi triturado em partículas entre 0,5 a $1 \mathrm{~cm}$, sendo transferidos para silos experimentais contendo $5 \mathrm{~kg}$ cada, armazenados à temperatura ambiente, sob proteção solar. Após a abertura do silo, coletaram-se amostras de $200 \mathrm{~g}$ das silagens, as quais foram utilizadas para identificação e quantificação da microbiota presente (fungos, bactérias, bacilos e leveduras), determinação de componentes bromatológicos (matéria seca, proteína bruta, fibra detergente neutro, fibra detergente ácido), $\mathrm{pH}$ e poder tampão. Os dados foram submetidos à análise de variância, sendo as médias comparadas pelo teste de Tukey, ao nível de 5\% de probabilidade. A maior prevalência $(\mathrm{p}<0,05)$ dos microrganismos ocorreu no tratamento que recebeu adição conjunta dos inoculantes bacteriano e enzimático. Os fungos encontrados pertencem aos gêneros Aspergillus, Fusarium, Penicillium, Pythium e Cladosporium, sendo os dois primeiros observados em maior porcentagem. Quanto aos componentes bromatológicos, a matéria seca, proteína bruta, fibra em detergente ácido e poder tampão não apresentaram diferença significativa $(\mathrm{p} \geq 0,05)$ entre os tratamentos. Os tratamentos que receberam inoculantes apresentaram os menores valores de fibra em detergente neutro $(p<0,05)$ e aqueles que receberam o inoculante enzimático apresentaram menores valores de $\mathrm{pH}$ $(\mathrm{p}<0,01)$. A adição de inoculante bacteriano e enzimático afetou alguns dos microrganismos presentes na microbiota associada às silagens, alterando, consequentemente, a FDN e o pH, dada a maior disponibilidade de substratos fermentativos.

PALAVRAS-CHAVES: Bactérias, fungos, enzimas, ensilagem, milho e microbiologia.

ABSTRACT

\section{INFLUENCE OF BACTERIAL-ENZYMATIC INOCULANT ON MICROBIOTA AND NUTRITIONAL QUALITY OF HUMID MAIZE GRAIN SILAGES}

The objective of this work was to evaluate the influence of bacterial-enzymatic inoculant on microbiota and nutritional quality of humid maize grain silages. The following treatments were applied to wet grain maize silages: 1) without inoculant; 2) with bacterial inoculant (Lactobacillus marry and Streptococcus faecalis); 3 ) with bacterial and enzymatic complex ( $\alpha$-galactosidase and $\beta$-mananase); and 4) only with enzymatic complex. The material was triturated in particles among 0.5 to $1 \mathrm{~cm}$, being 
transferred to experimental silos containing $5 \mathrm{~kg}$ each, stored in room temperature and under sun protection. After opening the silo, samples of $200 \mathrm{~g}$ were collected from the silages, which were used for identification and quantification of the present microbiota (fungus, bacteria, bacillus and yeasts), determination of bromatological components (dry matter, crude protein, neutral detergent fiber, acid detergent fiber), $\mathrm{pH}$ and buffering capacity. The data were submitted to variance analysis, being the averages compared by Tukey test, at level of 5\% probability. The largest prevalence $(p<0.05)$ of microorganisms occurred in the treatment that received combined addition of the bacterial and enzymatic inoculants. The fungus found belonged to Aspergillus, Fusarium, Penicillium, Pythium and Cladosporium, being the first two in larger percentage. The dry matter, crude protein, acid detergent fiber, and buffering capacity did not present significant difference $(\mathrm{p} \geq 0.05)$ among the treatments. The treatments that received inoculants presented the smallest fiber values in neutral detergent $(p<0.05)$ and those that received the enzymatic inoculant presented smaller $\mathrm{pH}$ values $(p<0.01)$. The addition of bacterial and enzymatic inoculantes affected some of the present microorganisms in the microbiota associated to the silages, altering consequently the FDN and the $\mathrm{pH}$, due to larger readiness of fermentative substrates.

KEY WORDS: Bacteria, fungus, enzymes, ensilage, maize and microbiology.

\section{INTRODUÇÃO}

A ensilagem de grãos úmidos de milho pode contribuir para solucionar os graves problemas de armazenagem de grãos em fazendas, onde normalmente ocorrem grandes perdas qualitativas e quantitativas em função do ataque de insetos e ratos. Além disso, a colheita dos grãos para ensilar proporciona antecipação na liberação de área agrícola com grandes benefícios em esquema com rotação de culturas e/ou integração agricultura e pecuária, além de reduzir significativamente as perdas no campo (JOBIM et al., 2001).

Segundo NUMMER (2001), a colheita de grãos úmidos de milho deve ser realizada quando este estiver com a umidade situada entre $30 \%$ e $40 \%$, sendo que os melhores resultados com silagens de grãos úmidos têm sido obtidos com umidade entre $32 \%$ e $35 \%$. Por sua vez, o tamanho de partícula dependerá da espécie ou da categoria animal que se pretende alimentar e do teor de umidade do grão. A moagem deve ser feita imediatamente após a colheita de todo o grão. Preferencialmente, deve ser moído e compactado no mesmo dia, visando a um produto de alta qualidade. A compactação pode ser feita com tratores e tem fundamental importância no resultado final da silagem. Uma boa silagem de grão úmido deve ter, no mínimo, $900 \mathrm{~kg}$ de silagem por metro cúbico, sendo que o ideal é ter entre 1.100 e $1.200 \mathrm{~kg}$.

Para JOBIM et al. (1997) e NUMMER (2001), a utilização de inoculante para silagem de grão úmido tem melhorado o tempo de conclusão da fermentação, que varia entre cinco e oito dias. Assim, com uma rápida fermentação, as perdas são reduzidas. Quando não é utilizado inoculante, esperam-se, no mínimo, 28 dias, ou seja, são pelo menos vinte dias a mais fermentando e perdendo qualidade. O milho colhido com $35 \%$ de umidade tem uma baixa concentração de bactérias lácticas, o que leva à ocorrência de ácidos butírico e propiônico, além de reações químicas que produzem $\mathrm{CO}_{2}$, água e consomem energia. Consequentemente, o tempo de armazenagem da silagem depende da compactação e da vedação do silo. Um silo fechado de forma adequada pode armazenar a silagem de grão úmido por vários anos. Entretanto, os produtores têm utilizado a silagem de grão úmido por um período máximo de dois anos.

De acordo com VILELA (1998), os inoculantes utilizados em silagens de grãos úmidos são bacterianos, compostos por bactérias acidoláticas associadas ou não a complexos enzimáticos, constituídos por celulases, amilases e hemicelulases, dentre outras. Esses aditivos são estimulantes da fermentação e não nutritivos. $\mathrm{O}$ princípio básico de atuação desses produtos consiste no aumento da disponibilidade de açúcares simples, via complexo enzimático, para que as bactérias tenham acesso, dessa forma, à produção de ácido láctico e rápida queda do pH no material ensilado. Podem também inibir o crescimento de outros microrganismos nas silagens, evitando a produção de micotoxinas, além de proporcionar uma maior taxa de estabilidade aeróbia e/ ou efeito positivo ao ambiente do rúmen animal.

Nesse sentido, grande variedade de aditivos tem sido recomendada com o intuito de se garantir melhor qualidade das silagens. Entretanto, deve-se considerar a eficácia e a viabilidade do aditivo. Atualmente, os inoculantes bacterianos são compostos por Lactobacillus plantarum, Lactobacillus casei, Enterococcus faecium e Pediococcus spp., Streptococcus faecium, 
Streptococcus faecalis, Lactobacillus sp., Lactobacilus buchneri e propionibactérias, enquanto os complexos enzimáticos são compostos por hemicelulase, celulase, amilase, $\alpha$-galactosidase e $\beta$-mananase (JOBIM et al., 2003; RODRIGUES et al., 2004; BERNARDES et al., 2005; KUNG et al., 2007).

Diversos autores observaram e acompanharam a dinâmica fermentativa de silagens inoculadas com Lactobacillus, verificando rápida elevação do número desses microrganismos, elevada produção de ácido lático, rápido declínio do $\mathrm{pH}$ e consumo de glicídeos solúveis em três a sete dias de fermentação (BOLSEN et al., 1992; KUNG et al., 2007). Da mesma forma, WEINBERG et al. (1999), TAYLOR et al. (2002) e KUNG et al. (2007) observaram que a adição do Lactobacillus bucheneri 40788 melhora a estabilidade aeróbica, aumentando a concentração de ácido acético e diminuindo as populações fúngicas.

A ocorrência de fungos em silagens está associada, principalmente, a falhas na compactação de materiais com alto conteúdo de matéria seca e com tamanho das partículas (MUCK \& SHINNERS, 2001; PEREIRA \& REIS, 2001). Os fungos, sobretudo as espécies dos gêneros Aspergillus, Fusarium e Penicillium, crescem nos fenos e nas silagens e produzem toxinas que podem acarretar problemas aos animais. No entanto, uma grande quantidade de fungos produtores de toxinas pode contaminar os cereais, principalmente em regiões de clima tropical (McDONALD et al., 1991; MAHANNA, 1994).

Fatores ambientais têm impacto predominante no crescimento de fungos, pois estes são cosmopolitas na natureza, podendo subsistir em matéria em decomposição, no solo, na vegetação e na água, desempenhando um papel crítico na epidemiologia das micotoxicoses. Umidade relativa muito elevada, substrato propício (rico em carboidrato), temperatura adequada, pH superior a cinco e ambiente sem circulação constante de ar favorecem o seu desenvolvimento. Consequentemente, de acordo com JOBIM et al. (2003), os maus-tratos nos processos de ensilagem, como o tipo de processamento (quebra, moagem, laminação, amassamento), podem aumentar essa quantidade de substrato disponível, e a má compactação, em conjunto com uma quantidade elevada de matéria seca, podem propiciar ambiente favorável para a produção de fungos e outros microrganismos produtores de toxinas. É importan- te salientar que a produção de toxinas só acontece em condições específicas de umidade, temperatura, substrato conveniente e oxigênio apropriado, sendo que as condições ótimas para a produção de toxinas são específicas para cada fungo. O fungo Fusarium sporotrichioides produz uma toxina sob condições de baixa temperatura, enquanto o Aspergillus flavus tem a habilidade de produzir toxinas a uma temperatura de $25^{\circ} \mathrm{C}$ e até mesmo sob condições desfavoráveis (MALLMANN, 1998).

Considerando a importância da ensilagem no contexto da armazenagem de grãos em propriedades rurais e os problemas decorrentes da incidência de microrganismos produtores de toxinas, o presente trabalho teve por objetivo avaliar a influência de inoculante bacteriano e complexo enzimático sobre a microbiota e a qualidade nutricional de silagens de grãos úmidos de milho.

\section{MATERIAL E MÉTODOS}

Desenvolveu-se o estudo no Centro de Ciências Agrárias da Universidade Federal de Alagoas, no período de outubro a dezembro de 2005, utilizando o híbrido de milho BRS 3551, colhido no estágio de grão úmido, aos 92 dias de cultivo. Os grãos foram fragmentados em partículas com 0,5 a $1,0 \mathrm{~cm}$ de diâmetro.

O delineamento experimental utilizado foi o inteiramente casualizado, desenvolvendo-se estudos dos seguintes tratamentos: 1) silagem de grãos úmidos de milho sem inoculante; 2) silagem de grãos úmidos de milho com inoculante bacteriano, composto de Lactobacilos casei liofilizado e Streptococcus faecalis; 3) silagem de grãos úmidos de milho com inoculante bacteriano mais complexo enzimático, composto de $\alpha$-galactosidase e $\beta$-mananase; 4) silagem de grãos úmidos de milho apenas com complexo enzimático; com cinco repetições em cada tratamento.

Procedeu-se ao enriquecimento das silagens de grãos úmidos de milho com um inoculante bacteriano composto de $750 \mathrm{mg}$ de Lactobacillus casei liofilizado (1010 UFC/g de matéria verde (MV)) e $750 \mathrm{mg}$ de Streptococcus faecalis (108 UFC/g de MV), e com complexo enzimático composto de $\alpha$-galactosidase (9.000 GaIAU) e $\beta$-mananase (15.000 MIAU). A mistura do(s) inoculante(s) ocorreu de forma uniforme nos grãos no ato da ensilagem. 
Os microssilos experimentais de garrafas PET, contendo $5 \mathrm{~kg}$ cada, foram mantidos em ambiente coberto, sob proteção da luz solar e roedores, e permaneceram fechados durante sessenta dias. Após a abertura dos microssilos, coletaram-se alíquotas de \pm 200 g de cada repetição, divididas, identificadas, acondicionadas em sacos plásticos, mantidas resfriadas em caixa de isopor e encaminhadas aos laboratórios de Fitopatologia, para identificação e quantificação da microflora presente (fungos, bactérias totais, bacilos e leveduras), e de Bromatologia, para determinação dos componentes bromatológicos das silagens (matéria seca, proteína bruta, fibra em detergente neutro e fibra em detergente ácido) e do poder tampão e potencial hidrogênionico.

$\mathrm{Na}$ análise e quantificação dos fungos associados ao material ensilado, utilizou-se o método do isolamento direto, sendo cinco fragmentos de grãos, obtidos da amostra de $100 \mathrm{~g}$ do material, dispostos equidistantemente em placa de Petri contendo meio de cultura BDA (batata-dextrose-ágar). Os fragmentos foram incubados sob regime de luz alternada (doze horas de claro/doze horas de escuro) durante sete dias à temperatura ambiente. Após o período de incubação, examinaram-se os fragmentos individualmente e, em seguida, procedeu-se a preparações das estruturas dos fungos presentes e à consequente identificação em exame microscópico, baseando-se em chaves taxonômicas segundo BARNETT \& HUNTER (1972) e HANLIN (1990). A estimativa da frequência dos fungos foi calculada a partir da fórmula: frequência $(\%)=n^{\circ}$ de amostras com ocorrência de fungos $/ n^{\circ}$ total de amostras por placa $\times 100$ (SENTHILKUMAR et al., 1993), obtendo-se, dessa forma, a frequência por repetição. Para o cálculo da frequência de espécies fúngicas, utilizou-se a fórmula anterior, considerando, para tanto, o número de colônias obtidas por espécie fúngica dividido pelo número total de colônias fúngicas observadas $\times 100$.

Quantificou-se a presença de bactérias totais, leveduras e Bacillus no material, por meio da técnica de diluição em série utilizando $1 \mathrm{~g}$ da amostra (ANDRADE et al., 2005). Para a quantificação de bactérias totais e leveduras, foi plaqueada a diluição de $10^{-4} \mathrm{em}$ placas de Petri contendo meio de cultura BDA sem e com adição de antibiótico, respectivamente. Para quantificar a população de Bacillus, a diluição foi submetida a banho-maria de $80^{\circ} \mathrm{C}$ por vinte minutos, com posterior distribuição em meio BDA, sem adição de antibiótico. As placas de Petri foram incubadas a 25 $\pm 2^{\circ} \mathrm{C}$, sob luminosidade contínua, sendo as populações quantificadas e expressas em unidades formadoras de colônias (ufc)/g de amostra.

Para a análise da qualidade nutricional, através de componentes bromatológicos, amostras com aproximadamente $100 \mathrm{~g}$ foram submetidas à secagem em estufa, sob ventilação forçada de ar a $65^{\circ} \mathrm{C}$ por 72 horas, para ser iniciada a determinação da matéria seca (MS), segundo o método proposto pela AOAC (1990). Determinou-se a proteína bruta $(\mathrm{PB})$ pelo processo micro kjeldahl, metodologia descrita por SILVA \& QUEIROZ (2002). Para o conteúdo de fibra em detergente ácido (FDA), foi utilizado o método proposto por VAN SOEST et al. (1967), utilizando ácido sulfúrico, para solubilizar os açúcares, amido, hemiceluloses e algumas pectinas, e detergente (CTAB - brometo de cetil trimetil amônio $\mathrm{C}_{19} \mathrm{H}_{42} \mathrm{BrN}$ ), para remover proteínas. $\mathrm{O}$ conteúdo de fibra em detergente neutro (FDN) foi determinado mediante a utilização de alfa-amilase termoestável e ureia para reduzir substancialmente a contaminação por amido, método esse descrito por VAN SOEST et al. (1991). Determinou-se o $\mathrm{pH}$ por um potenciômetro digital da marca $\mathrm{TecNal} \AA$, diretamente nos extratos constituídos de $50 \mathrm{~g}$ do material para 50 $\mathrm{mL}$ de água deionizada, antes da filtragem. $\mathrm{O}$ poder tampão foi obtido através da metodologia proposta por PLAYNE \& MCDONALD (1966).

Os dados obtidos nas análises foram submetidos à análise de variância, sendo as médias comparadas pelo teste de Tukey, ao nível de 5\% de probabilidade. Transformaram-se as médias dos dados microbiológicos para log ufc/g de amostra.

\section{RESULTADOS E DISCUSSÃO}

Os dados de ocorrência de fungos, leveduras, bactérias totais e Bacillus obtidos das silagens de grãos úmidos de milho tratadas ou não com inoculantes bacteriano-enzimáticos são apresentados na Tabela 1.

Os valores quantificados para bactérias totais foram significativamente superiores nos tratamentos com adição do inoculante bacteriano (Tabela 1). Tal fato já era esperado, em virtude de o inoculante, por si só, conter bactérias, e, além disso, corrobora com o 
observado por diversos autores sobre a dinâmica fermentativa de silagens inoculadas com Lactobacillus, em que verificaram rápida elevação do número desses microrganismos em um curto período de tempo (BOLSEN et al., 1992; KUNG JR. et al., 1993). A quantidade de bactérias totais e de Bacillus foi significativamente maior com a mistura do inoculante bacteriano e o complexo enzimático, ou seja, possivelmente a adição deste ao processo resulta em uma maior disponibilidade de açúcares simples, que são nutrientes importantes para o desenvolvimento dessas bactérias (VILELA, 1998).

TABELA 1. Microflora epífita das silagens de grão úmido de milho, enriquecidas ou não com inoculantes bacteriano-enzimáticos

\begin{tabular}{|c|c|c|c|c|c|c|c|}
\hline \multirow[b]{2}{*}{ Tratamentos $^{1}$} & \multicolumn{2}{|c|}{ Bactérias } & \multicolumn{5}{|c|}{ Fungos } \\
\hline & Totais & Bacillus & Leveduras & Fusarium spp & Aspergillus sp. & $\begin{array}{c}\text { Penicillium } \\
\text { spp. }\end{array}$ & Outros \\
\hline & \multicolumn{3}{|c|}{-------- ufc / g de amostra ---------- } & \multicolumn{4}{|c|}{------------------------ \% 0} \\
\hline SGUM & $0,0 \mathrm{c}$ & $0,0 \mathrm{~b}$ & $0,0 \mathrm{a}$ & $20,0 \mathrm{a}$ & $0,0 \mathrm{~b}$ & $0,0 \mathrm{c}$ & $0,0 \mathrm{c}$ \\
\hline SGUM+IB & $7,4 \mathrm{~b}$ & $0,4 \mathrm{~b}$ & $0,0 \mathrm{a}$ & $0,0 \mathrm{~b}$ & $8,0 \mathrm{a}$ & $8,0 \mathrm{~b}$ & $4,0 \mathrm{~b}$ \\
\hline $\mathrm{SGUM}+\mathrm{IB}+\mathrm{CE}$ & 19,4 a & $18,0 \mathrm{a}$ & $0,2 \mathrm{a}$ & 24,0 a & $8,0 \mathrm{a}$ & $20,0 \mathrm{a}$ & $0,0 \mathrm{c}$ \\
\hline SGUM+CE & $1,0 \mathrm{c}$ & $0,0 \mathrm{~b}$ & $0,0 \mathrm{a}$ & $4,0 \mathrm{~b}$ & $0,0 \mathrm{~b}$ & $8,0 \mathrm{~b}$ & $8,0 \mathrm{a}$ \\
\hline
\end{tabular}

Médias seguidas pela mesma letra na vertical não diferem entre si pelo teste de Tukey, ao nível de $5 \%$ de probabilidade. Para a análise estatística os dados foram transformados para $\log (\mathrm{x}+1)$.

${ }^{1} \mathrm{SGUM}=$ silagem de grão úmido de milho; $\mathrm{IB}=$ inoculante bacteriano; $\mathrm{CE}=$ complexo enzimático.

Em relação à frequência de fungos, observou-se variação significativa entre os tratamentos estudados quando considerados os fungos Fusarium spp., Aspergillus flavus, Penicillium spp. e outros, com exceção das leveduras, em que não foram verificadas diferenças entre os tratamentos (Tabela 1). Para Fusarium spp., o tratamento sem inoculantes e com a adição conjunta dos inoculantes bacteriano e enzimático apresentou frequências do fungo significativamente maiores do que nos demais tratamentos. Para Aspergillus flavus, as maiores frequências do fungo foram observadas nos tratamentos com adição de inoculante bacteriano, com e sem adição do complexo enzimático, as quais diferiram significativamente dos demais tratamentos. Por fim, para Penicillium spp., registraram-se valores de frequência significativamente elevados em todos os tratamentos inoculados, quando comparados com o tratamento-controle, sem adição de inoculantes. Diferentemente deste trabalho, BOLSEN et al. (1992), usando inoculantes bacterianos e enzimáticos, relataram que os tratamentos com uso dos inoculantes não apresentaram efeito na contagem de microrganismos e nas características de fermentação durante o período de ensilagem. Da mesma forma, OUDE ELFERINK et al. (1999) mostraram que a utilização de Lactobacilos sp. pode também produzir outros metabólicos com atividades antifúngicas. Alguns inoculantes bacterianos, como o Lactobacillus buchneri, têm a capacidade de produzir ácido acético e, às vezes, ácido propiônico, que são mais efetivos na inibição do crescimento de leveduras e fungos do que o ácido láctico (WEINBERG et al., 1999; KUNG \& RANJIT, 2001; TAYLOR et al., 2002).

A presença de fungos altera a concentração de nutrientes nas silagens, principalmente em relação à concentração de carboidratos solúveis e vitaminas. JOBIM et al. (1997), estudando a incidência de fungos e leveduras nas silagens de espigas e grãos úmidos de milho em diferentes períodos de amostragem, observaram que, após a abertura dos silos, as silagens apresentavam 2,0 e 1,4 log ufc de fungos/g de MV para silagens de espiga e grãos, respectivamente. Constataram, ainda, que o desenvolvimento de leveduras e fungos nas respectivas silagens aumentou significativamente após dois dias de abertura dos silos.

No presente estudo foi detectada a presença de leveduras em pequenas proporções (Tabela 1). As leveduras são os principais microrganismos envolvidos na deterioração aeróbia das silagens e, segundo WOOLFORD (1990), silagens com contagem de leveduras 
superiores a 5,0 log ufc/g são altamente susceptíveis à deterioração. De maneira contrária, HENDERSON (1993) afirma que não se pode considerar como fator decisivo que silagens com mais de $10^{5} \mathrm{UFC} / \mathrm{g}$ de $\mathrm{MV}$ sejam mais propensas à deterioração, uma vez que silagens com menores populações de leveduras também podem deteriorar-se rapidamente. De acordo com ARCHUNDIA \& BOLSEN (2001), outro fator importante para o estabelecimento das leveduras que assimilam o lactato e, consequentemente, para a deterioração do material ensilado é a difusão de $\mathrm{O}_{2}$ durante a armazenagem.

A inoculação com bactérias homofermentativas produtoras de ácido lático pode melhorar a qualidade das silagens promovendo rápida e eficiente produção de ácido láctico e redução do pH (RODRIGUES et al., 2004). No entanto, alta concentração de ácido láctico nem sempre tem efeito positivo sobre a estabilidade aeróbia e a inibição do crescimento de leveduras (WOOLFORD, 1976).

RANJIT \& KUNG (2000), trabalhando com inoculante bacteriano, observaram diminuição de ácido lático, aumento de ácido acético e menor crescimento de leveduras dos gêneros Saccharomyces, Candida, Cryptococcus e Pichia, prevenindo a deterioração aeróbia quando as silagens foram expostas ao ar. Da mesma forma, WEINBERG et al. (1999), TAYLOR et al. (2002) e KUNG et al. (2007) observaram que a adição do L. bucheneri 40788 melhora a estabilidade aeróbia, aumentando a concentração de ácido acético e diminuindo as populações fúngicas. Outros fungos também foram observados associados às silagens neste estudo, sendo esses fungos pertencentes aos gêneros Cladosporium e Pythium, os quais não são relatados na literatura especializada como importantes no processo de ensilagem.

No presente estudo, foi verificada a presença de fungos produtores de toxinas, tais como Fusarium, Aspergillus e Penicillium, que atuam como infectantes de grãos de cereais (Figura 1). Da mesma forma, WOOLFORD (1990) pesquisou mensalmente a microbiota fúngica de 130 amostras de milho, sendo que os gêneros mais encontrados foram $\mathrm{Fu}$ sarium; Penicillium e Aspergillus, respectivamente em $83,8 \% ; 55,3 \%$ e $40,7 \%$ das amostras analisadas. MUCK \& SHINNERS (2001) demonstraram que o gênero fúngico mais encontrado no milho recém- colhido foi o Fusarium, seguido por Aspergillus e Penicillium.

A contaminação dos grãos por fungos pode ocorrer ainda no campo ou durante o armazenamento do produto. Os fungos de armazenamento Aspergillus, Penicillium, Rhizopus e Mucor são encontrados em grande número em armazéns, moinhos, silos, moendas, elevadores, equipamentos e nos lugares onde são processados produtos agrícolas (MÁRCIA \& LÁZZARI, 1998). De acordo com RODRÍGUEZ-AMAYA \& SABINO (2002), os fungos mais frequentemente isolados no milho e seus derivados em todo o Brasil são Fusarium, Aspergillus, Penicillium, Rhizopus, Acremonium, Cladosporium, Neurospora e Paecilomyces. Dentre os gêneros isolados de cereais, os mais frequentemente associados à produção de micotoxinas são Aspergillus, Penicillium e Fusarium (KIESSLING, 1986). A identificação das espécies fúngicas contaminantes é um importante sinalizador quanto à presença de micotoxinas nos substratos, indicando um caminho para a prevenção da produção das mesmas (FARIAS et al., 2000).

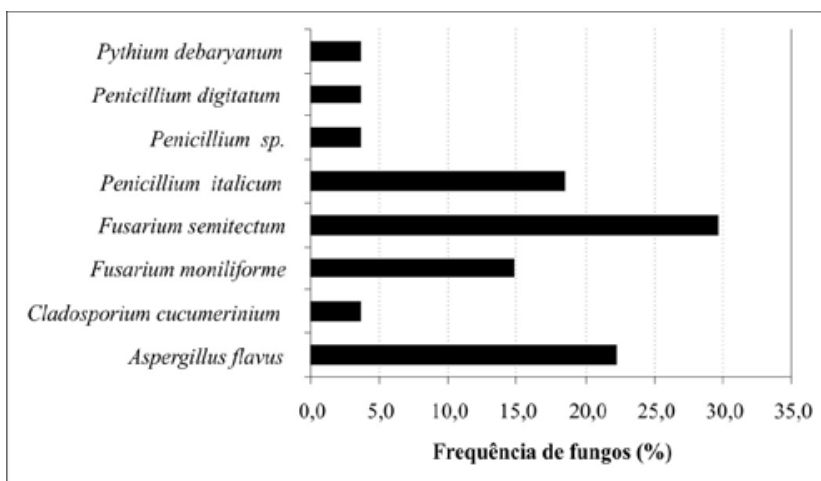

FIGURA 1. Frequência de espécies fúngicas associadas às silagens de grão úmido de milho após a abertura do silo, considerando todos os tratamentos analisados.

A Figura 2 ilustra alguns fungos encontrados no presente trabalho. As micotoxinas produzidas por essas espécies fúngicas são metabólitos secundários que podem apresentar atividade mutagênica, carcinogênica e teratogênica, sintetizados no final da fase de crescimento exponencial de alguns fungos (FARIAS et al., 2000). De acordo com ADEBAJO et al. (1994), MÁRCIA \& LÁZARRI (1998) e FARIAS et al. (2000), os gêneros Aspergillus, Penicillium e Fusarium são os 
mais frequentemente isolados de milho e derivados. Praticamente todas as amostras de silagens de grãos úmidos de milho analisadas apresentaram Aspergillus, Penicillium e Fusarium. Segundo MÁRCIA \& LÁZZARI (1998), Fusarium é considerado um fungo de campo que invade grãos e sementes durante o amadurecimento, sendo o dano causado antes da colheita. De acordo com MERONUCK (1987), espécies de $A s$ - pergillus são consideradas iniciadoras de deterioração de sementes e grãos, podendo crescer com baixo teor de água seguido pela contaminação por Penicillium, com umidade relativa mais elevada decorrente da atividade metabólica dos primeiros invasores. Esses fungos são potencialmente micotoxigênicos e sua presença em silagens de grãos úmidos de milho é preocupante.
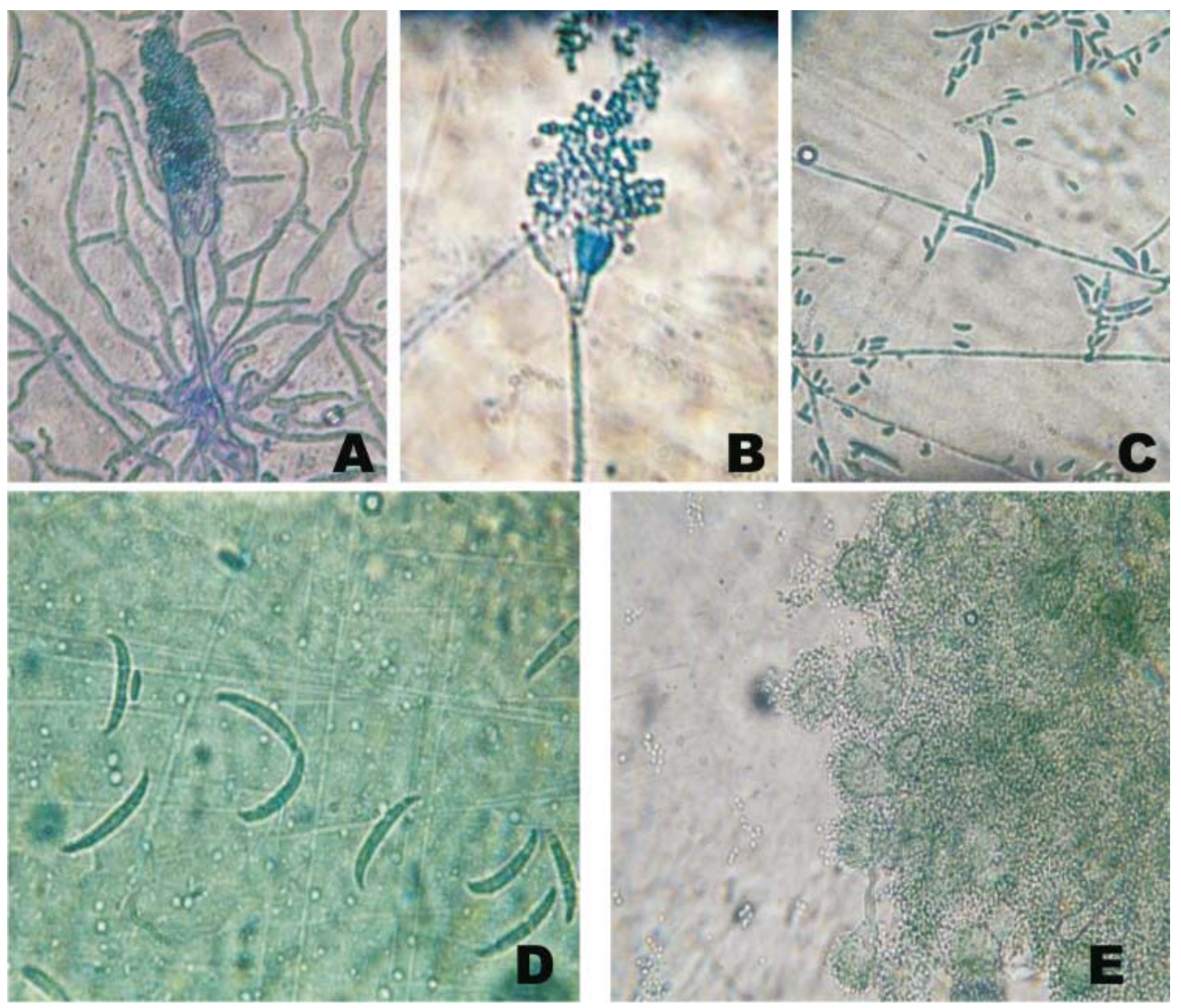

FIGURA 2. Fungos encontrados em silagens de grão úmido de milho, aditivadas ou não com inoculantes bacteriano-enzimaticos: A. Penicillium digitatum, B. Penicillium italicum, C. Fusarium semitectum, D. Fusarium moniliforme e E. Aspergillus flavus.

Os resultados da composição bromatológica da silagem de grão úmido de milho aditivada ou não com inoculantes bacteriano-enzimático evidenciam a atuação desses microrganismos após o processo de ensilagem (Tabela 2). Não foram observadas diferenças estatísticas ( $p>0,05)$ nos valores de matéria seca (MS), proteína bruta (PB), fibra em detergente ácido (FDA) e poder tampão (PT). De maneira similar, KUNG et al. (1993), PEDROSO et al. (2000) e ÍTAVO et al. (2005) observaram que a adição de inoculantes bacterianos e enzimáticos em silagem de grãos úmidos de milho não promoveram alterações nos valores de matéria seca 
a ponto de diferir estatisticamente, nem mesmo nos teores médios obtidos para PB, FDA e PT das diferentes silagens avaliadas, que no presente estudo foram de 7,24 \%, 3,58 \% e 43,31, respectivamente. Por sua vez, ITAVO et al. (2006) observaram que a adição dos inoculantes também não promoveu alterações na $\mathrm{PB}$ $(6,96 \%$ e $7,32 \%)$, na FDA $(4,44 \%$ e $4,54 \%)$ e no $\mathrm{pH}$
(3,94 e 3,92 unidades), nem reduziu as perdas da MS das silagens, possivelmente em virtude de diferentes variedades, características edafoclimáticas e época do plantio. Resultados similares foram obtidos por PEDROSO et al. (2000), avaliando a silagem de sorgo com inoculante bacteriano.

TABELA 2. Teores de matéria seca (MS), proteína bruta (PB), fibra em detergente neutro (FDN), fibra em detergente ácido (FDA), potencial hidrogênionico $(\mathrm{pH})$ e poder tampão $(\mathrm{PT})$ das silagens de grãos úmidos de milho aditivadas ou não com inoculantes bacterianoenzimáticos

\begin{tabular}{lcccccc}
\hline \multirow{2}{*}{ Tratamentos $^{1}$} & \multicolumn{4}{c}{ Componentes bromatológicos } & \multirow{2}{*}{ pH } & PT \\
\cline { 2 - 5 } & MS & PB & FDA & FDN & & e.mg / 100g MS \\
\hline SGUM & $52,47 \mathrm{a}$ & $6,92 \mathrm{a}$ & $3,38 \mathrm{a}$ & $39,50 \mathrm{a}$ & $3,85 \mathrm{a}$ & $43,63 \mathrm{a}$ \\
SGUM+IB & $53,07 \mathrm{a}$ & $6,62 \mathrm{a}$ & $3,62 \mathrm{a}$ & $32,49 \mathrm{~b}$ & $3,83 \mathrm{a}$ & $44,15 \mathrm{a}$ \\
SGUM+IB+CE & $51,52 \mathrm{a}$ & $7,01 \mathrm{a}$ & $3,57 \mathrm{a}$ & $32,67 \mathrm{~b}$ & $3,81 \mathrm{ab}$ & $43,07 \mathrm{a}$ \\
SGUM+CE & $53,09 \mathrm{a}$ & $8,42 \mathrm{a}$ & $3,78 \mathrm{a}$ & $33,98 \mathrm{~b}$ & $3,78 \mathrm{~b}$ & $42,40 \mathrm{a}$ \\
CV(\%) & 3,86 & 18,88 & 14,51 & 9,83 & 0,49 & 3,70 \\
Probabilidade & $\mathrm{ns}$ & $\mathrm{ns}$ & $\mathrm{ns}$ & 0,05 & 0,01 & $\mathrm{~ns}$ \\
\hline
\end{tabular}

Médias seguidas pela mesma letra na vertical não diferem entre si pelo teste de Tukey, aos níveis de 1 ou $5 \%$ de probabilidade.

${ }^{1} \mathrm{SGUM}=$ silagem de grão úmido de milho; $\mathrm{IB}=$ inoculante bacteriano; $\mathrm{CE}=$ complexo enzimático; $\mathrm{CV}$ = coeficiente de variação.

Na fração FDN foi observada diferença estatística entre os tratamentos $(p<0,05)$, sendo que os que receberam os inoculantes apresentaram os menores valores para essa variável. De maneira similar, SHEPERD \& KUNG (1996), ao utilizarem inoculantes enzimáticos contendo atividade de celulase e hemicelulase, observaram redução dos teores de FDN e FDA, o que não ocorreu para a adição conjunta bacteriana-enzimática, relatando que os efeitos foram inconsistentes sobre a composição da fração FDN da silagem de grão úmido de milho.

Os menores valores de FDN foram observados nas silagens tratadas com os inoculantes, compostos de Lactobacilos casei, Streptococcus faecalis, Alfagalactosidase e Beta-mananase. Este fato deve-se, provavelmente, à maior disponibilização de substratos fermentativos nessas silagens, como celulose e hemicelulose, que podem ter ocorrido por um conjunto de eventos ainda não totalmente elucidados neste estudo, como o inter-relacionamento entre microrganismos, enzimas ou outros constituintes químicos da própria espécie vegetal, que, juntos, influenciam a velocidade da queda do $\mathrm{pH}$ e, consequentemente, a ação dos microrganismos e das enzimas no universo fermentativo.

Independente do tipo de tratamento utilizado, todas as silagens avaliadas foram bem preservadas no presente estudo, pois apresentaram $\mathrm{pH}$ abaixo de 4,2, demonstrando boa qualidade da fermentação para SGUM (KUNG et al., 2003).

Tais efeitos também foram considerados por SANDERSON (1993), em estudo sobre a inoculação microbiana (Lactobacillus plantarum e Streptococus faecium) em silagem de grãos úmidos de milho, ensilada por 30 e 160 dias, observando que a inoculação diminuiu o $\mathrm{pH}$ da silagem. GIMENES et al. (2005) também encontraram resultados parecidos com os do presente trabalho, em que os tratamentos com inoculantes enzimáticos e controle apresentaram, na abertura, $\mathrm{o}$ menor $(3,28)$ e o maior $\mathrm{pH}(3,42)$, respectivamente.

De maneira similar aos resultados obtidos neste trabalho, estudos realizados por SCHAEFER et al. 
(1989) demonstraram que as silagens de grãos úmidos de milho foram responsivas à adição de inoculantes bacterianos em relação à contagem da população microbiana. Entretanto, não se detectaram efeitos na qualidade nutricional do material ensilado. Em contrapartida, KUNG \& RANJIT (2001) destacam que os inoculantes bacterianos não somente têm melhorado a qualidade das silagens como também têm aumentado a recuperação de matéria seca.

\section{CONCLUSÕES}

A adição conjunta do inoculante bacteriano e complexo enzimático propiciou um aumento no crescimento das bactérias, do Aspergillus e Penicillium, e não promoveu aumento no crescimento do Fusarium e das leveduras.

Os inoculantes não afetaram a PB e a FDA, porém reduziram a FDN, provavelmente pela ação dos microrganismos sobre os substratos fermentativos presentes nessas silagens.

A adição dos inoculantes resultou na melhora dos padrões fermentativos com menores níveis de $\mathrm{pH}$ e PT. Contudo, faz-se necessário um estudo mais detalhado do padrão fermentativo das silagens aditivadas e em conjunto uma análise econômica da utilização dos referidos inoculantes.

\section{AGRADECIMENTOS}

À Fundação de Amparo à Pesquisa do Estado de Alagoas (FAPEAL); ao Laboratório de Enzimologia Aplicada e Análises Bromatólogicas e ao Laboratório de Fitopatologia, ambos da Universidade Federal de Alagoas.

\section{REFERÊNCIAS}

ADEBAJO, L. O.; IDOWU, A. A.; ADESANAYA, O. O. Mycoflora, and mycotoxins production in Nigerian corn and corn based snacks. Mycopathologia, v. 126, p. 183-192, 1994.

ANDRADE, D. E. G. T.; MICHEREFF, S. J.; BIONDI, C. M.; NASCIMENTO, C. W. A.; SALES JR, R. Frequência de fungos associados ao colapso do meloeiro e relação com características físicas, químicas e microbiológicas dos solos. Summa Phytopathologica, v. 31, p. 327-333, 2005.
ASSOCIATION OF OFFICIAL ANALYTICAL CHEMISTS AOAC. Official methods of analysis. 10. ed. Washington, D.C.: AOAC,1990. p. 1015.

ARCHUDIA, M. E. U.; BOLSEN, K. K. Aerobic deterioration of silage: processes and prevention. In: ANNUAL SYMPOSIUM, 17. 2001, Thurmpton Nottingham, UK, Proceedings... 2001. p.127144. Available in: <www.nupel.uem.br/pos-ppz/forragens-08-03. pdfwww.cababstractsplus.org/abstracts/Abstract.aspx.> Access in: 22 out. 2008.

BARNETT, H. L.; HUNTER, B. B. Illustrated genera of imperfect fungi. 3. ed. Burgess Publishing Company: Minnesota, 1972. $241 \mathrm{p}$.

BOLSEN, K. K.; LIN, C.; BRENT, B. E.; FEYERHERM, A. M.; URBAN, J. E.; AIMUTIS, W. R. Effect of silage additives on the microbial succession and fermentation process of alfafa and corn silage. Journal of Dairy Science, v. 75, n. 11, p. 3066-3083, 1992.

BERNADES, T. F.; REIS, R. A.; MOREIRA, A. L. Perfil fermentativo e microbiológico das silagens do capim marandu aditivadas com polpa cítrica peletizada. Scientia Agricola, doi: 10.1590/S0103-90162005000300003, 2005. Online, v. 62, n. 3, p. $214-220$.

FARIAS, A. X.; ROBBS, C. F.; BITTENCOURT, A. M.; ANDERSEN, P. M.; CORRÊA, T. B. S. Contaminação endógena por Aspergillus spp. em milho pós-colheita no Estado do Paraná. Pesquisa Agropecuária Brasileira, v. 35, n. 3, p. 617-621, 2000.

GIMENES, A. L. G.; MOREIRA, F. B.; MIZUBUTI, I. Y.; PEREIRA, E. S. Efeitos da utilização de inoculantes bacteriano e enzimático em silagens de milho sobre os teores de proteína e fibra, digestibilidade dos nutrientes, $\mathrm{pH}$, fermentação e estabilidade aeróbica. Seminário: Ciências Agrárias, Londrina, v. 26, n. 4, p. 601-610, out./dez. 2005.

HANLIN, B. T. Illustrated genera of Ascomycetes. St Paul: APS Press, 1990.

HENDERSON, N. Silage additives. Animal Feed Science and Technology, v. 45, p. 35-56, 1993.

ÍTAVO, C. C. B. F.; MORAIS, M. G. M.; ÍTAVO, L. C. V.; SOUZA, A. R. D. L.; DAVY, F. C. A.; ALBERTINI, T. Z.; COSTA, C.; LEMPP, B.; JOBIM, C. C. Parâmetros fermentativos de silagens de grãos úmidos de milho com ou sem o uso de aditivo microbiano. In: REUNIÃO ANUAL DA SOCIEDADE BRASILEIRA DE ZOOTECNIA, 40., 2005, Santa Maria. Anais... Santa Maria: Sociedade Brasileira de Zootecnia, CD-ROM. Forragicultura. FOR - 248, 2005. 
ITAVO, C. C. B. F.; MORAIS, M. G. M.; ÍTAVO, L. C. V.; SOUZA, A. R. D. L.; DAVY, F. C. A.; ALBERTINI, T. Z.; COSTA, C.; LEMPP, B.; JOBIM, C. C. Padrão de fermentação e composição química de silagens de grãos úmidos de milho e sorgo submetidas ou não a inoculação microbiana. Revista Brasileira Zootecnia, v. 35, n. 3, p. 655-664, 2006.

JOBIM, C. C.; BRANCO, A. B.; SANTOS, G. T. Silagem de grãos úmidos na alimentação de bovinos leiteiros. In: SIMPÓSIO GOIANO SOBRE MANEJO E NUTRIÇÃO DE BOVINOS DE CORTES E LEITE, 5., 2003, Goiânia, GO, p. 357-376. Disponível em: www.cbna.com.br/publicacoes.phphttp://www.nupel.uem.br/ graosumidos.pdf. Acesso em: 12 nov. 2008.

JOBIM, C. C.; CECATO, U.; CANTO, M. W. Utilização de silagem de grãos de cereais na alimentação animal. In: SIMPÓSIO SOBRE PRODUÇÃO E UTILIZAÇÃO DE FORRAGENS CONSERVADAS, 2001, Maringá. Anais... Maringá: CCA/UEM/DZO, p.146176. 2001. Disponível em: www.cpap.embrapa.br/agencia/congressovirtual/pdf/portugues/03pt06.pdf. Acesso em: 10 out. 2009.

JOBIM, C. C.; REIS, R. A.; RODRIGUES, L. R. A.; SCHOCKENITURRINO, R. P. Presença de microrganismos na silagem de grãos úmidos de milho ensilado com diferentes proporções de sabugo. Pesquisa Agropecuária Brasileira, v. 32, n. 2, p. 201-204, fev. 1997.

KIESSLING, K. H. Biochemical mechanism of action of mycotoxins. Pure and Applied Chemistry, v. 58, n. 2, p. 327-338, 1986.

KUNG, L.; CHEN, J. H.; KRECK, E. M. Effect of microbial inoculants on the nutritive value of corn silage for lactating dairy cows. Journal of Dairy Science, v. 76, n. 12, p. 3763-3770, 1993.

KUNG, L.; RANJIT, N. K. The effect of Lactobacilos buchneri and others additives on the fermentation and aerobic stability of barley silage. Journal of Dairy Science, v. 84, n. 5, p. 1149-1155, 2001.

KUNG JR. L.; STOKES, M. R.; LIN, C. J. Silage additives. In: BUXTON, D. R.; MUCK, R. E.; HARRISON, J. H. (Eds.). Silage science and technology. Madison: ASA-CSSA-SSSA, 2003. v. 42, p. 305-360.

KUNG, L. JR.; SCHMIDT, R. J.; EBLING, T. E.; HU, W. The effect of Lactobacilos buchneri 40788 on the fermentation and aerobic stability of ground and whole high-moisture corn. Journal of Dairy Science, v. 90, p. 2309-2314, 2007.

MAHANNA, B. Proper management assures high-quality feeds. Feedstuffs, v. 10, p. 12-56, 1994.

MALLMANN, C. A. Fight mycotoxins with strict prevention. University Federal de Santa Maria. Available in: http:// www.management/mycotoxins.htm. 1998. Access in: 22 maio 2008.

MÁRCIA, B. A.; LÁZZARI, F. A. Monitoramento de fungos em milho em grãos, grits e fubá. Revista Ciência e Tecnologia de Alimentos, v. 18, n. 4, p. 363-367, 1998.
MCDONALD, J. W.; DONG, H.; FAZZARO, A.; XIANG, C.; KORSMEYAER, S.; JACQUIN, M. F. Cyclosporine induces neuronal apoptosis and selective oligodendrocyte death in cortical cultures. Annimal Neurology, v. 40, p. 750-758, 1991.

MERONUCK, R. A. The significance of fungi in cereal grains. Plant Disease, v. 71, p. 287-291, 1987.

MUCK, R. E.; SHINNERS, K. J. Conserved forage (silage and hay): progress and priorities. In: INTERNATIONAL GRASSLAND CONGRESS, 19., 2001, São Pedro. Proceedings... Piracicaba: Brazilian Society of Animal Husbandry, 2001. p. 753-762. Available in: <www.internationalgrasslands.org/publications/ pdfs/tema21_1.pdf.>AAccess in: 23 nov. 2008.

NUMMER, F. I. Silagem de grão úmido de milho. In: SEMINÁRIO NACIONAL DE DESENVOLVIMENTO DA SUINOCULTURA, 9., 2001, Gramado, RS, Anais... Gramado, RS. 2001. p. 29-43. Disponível em: <www.scielo.br/scielo.php?script=sci arttext\&pid=S0102...lng. $>$ Acesso em: 18 out. 2008.

OUDE ELFERINK, S. J. W. H.; DRIEHUIS, F.; KROONEMAN, J.; GOTTSCHAL, J. C.; SPOELSTRA, S. F. Lactobacillus buchneri can improve the aerobic stability of silage via a novel fermentation pathway: the anaerobic degradation of lactic acid to acetic acid and 1,2-propanediol. In: INTERNATIONAL SILAGE CONFERENCE, 12., 1999, Uppsala. Proceedings... Uppsala: Swedwn, 1999. p. 266-267. Variable in: <http://aem.asm.org/cgi/ content/full/67/1/125.> Access in: 15 nov. 2008.

PLAYNE, M. J. C.; MCDONALD, P. The buffering constituents of herbage and silage. Journal Science of Food and Agriculture, v. 17, p. $262-268,1966$.

PEDROSO, A. F.; FREITAS, A. R.; SOUZA, G. B. Efeito de inoculante bacteriano sobre a qualidade da silagem e perda de matéria seca durante a ensilagem de sorgo. Revista Brasileira Zootecnia, v. 29 , n. 1 , p. $48-52$, jan.-fev. 2000.

PEREIRA, J. R. A.; REIS, R. A. Produção de silagem pré-secada com forrageiras temperadas e tropicais. In: SIMPÓSIO SOBRE PRODUÇÃO E UTILIZAÇÃO DE FORRAGENS CONSERVADAS, Maringá, 2001. Anais... Maringá: Universidade Estadual de Maringá, 2001.p. 64. Disponível em: <http://www.nupel.uem.br/ pre-secadas.pdf. $>$ Acesso em: 17 out. 2008.

RANJIT, N. K.; KUNG Jr., L. The effect of Lactobacilos buchneri, Lactobacilos plantarum, or a chemical preservative on the fermentation and aerobic stability of corn silage. Journal of Dairy Science, v. 83, n. 3, p. 526-535, 2000.

RODRIGUES, P. H. M.; ALMEIDA, L. F. S.; LUCCI, C. S.; MELOTTI, L.; LIMA, F.R. Efeitos da adição de inoculantes microbianos sobre o perfil fermentativo da silagem de alfafa adicionada de polpa cítrica. Revista Brasileira de Zootecnia, v. 33, n. 6, p. 1646-1653, 2004.

RODRÍGUEZ-AMAYA, D. B.; SABINO, M. Mycotoxins research in Brazil: the last decade in review. Brazilian Journal of Microbiology, v. 33, n. 1, p. 1-11, fev. 2002. 
SANDERSON, M. Aerobic stability and in vitro fiber digestibility of microbially inoculated corn and sorghum silages. Journal of Dairy Science, v. 71, p. 505-514, 1993.

SCHAEFER, D. M.; BROTZ, P. G.; ARP, S. C.; COOK, D. K. Inoculation of corn silage and high-moisture corn with lactic acid bacteria and its effect on the subsequent fermentation and on feedlot performance of beef steers. Animal Feed Science and Technology, v. 25, n. $1 / 2$, p. $23-38,1989$.

SENTHILKUMAR, K.; UDAYAN, K.; MANIAN, S. Successional patern of mycoflora associated with litter degradation in a Cymbopogon caesius dominated tropical grassland. Tropical Grass, v. 27, n. 27 , p. 121-127, 1993.

SHEPERD, A. C.; KUNG, L. An enzyme additive for corn silage: Effects on silage composition and animal performance. Journal of Dairy Science, Savoy, v. 79, p. 1760-1766, 1996.

SILVA, D. J.; QUEIROZ, A. C. Análise de alimentos: métodos químicos e biológicos. 3. ed. Viçosa: UFV, 2002. p. 235.

TAYLOR, C. C.; RANJIT, N. J.; MILLS, J. A. The effect of treating whole-plant barley with Lactobacilos buchneri 40788 on silage fermentation, aerobic stability, and nutritive value for dairy cows. Journal of Dairy Science, v. 85, p. 1793-1800, 2002.
VAN SOEST, P. J. Development of a comprrehensive sytem of feed analyses and its application to forages. Journal of Animal Science, v. 26, n. 1, p. 119-128, 1967.

VAN SOEST, P. J.; ROBERTSON, J. B.; LEWIS, B. A. Methods for dietary fiber, neutral detergent fiber, and nonstarch polysaccharides in relation to animal nutrition. Journal of Dairy Science, v. 74, n. 10, p. 3583-3597, 1991.

VILELA, D. Aditivos para silagem de plantas de clima tropical. In: REUNIÃO ANUAL DA SOCIEDADE BRASILEIRA DE ZOOTECNIA, 35., 1998, Botucatu, SP. Anais... Botucatu: Sociedade Brasileira de Zootecnia, 1998. p. 73-108.CD-ROM.

WEINBERG, Z. G.; SZAKACS, G.; ASHBELL, G.; HEN, Y. The effect of Lactobacilos buchneri and L. plantarum, applied at ensiling, on the ensiling fermentation and aerobic stability of wheat and sorghum silages. Journal of Industrial Microbiology \& Biotechnology, v. 23, n. 3, p. 218-222, 1999.

WOOLFORD, M. K. A preliminary investigation into the role of yeasts in the ensiling process. Journal of Applied Bacteriology, v. 41, p. 29-36, 1976.

WOOLFORD, M. K. The detrimental effects of air on silage. Journal of Applied Bacteriology, v. 68, n. 2, p. 101-116, 1990. 